\title{
Lung Cancer Heterogeneity in Modulation of Th17/IL17A Responses
}

\author{
Dominique Armstrong ${ }^{1 \dagger}$, Cheng-Yen Chang ${ }^{1 \dagger}$, Donald R. Lazarus ${ }^{1,2}$, David Corry ${ }^{1,2,3,4}$ and \\ Farrah Kheradmand ${ }^{1,2,3,4 *}$ \\ ${ }^{1}$ Department of Medicine, Baylor College of Medicine, Houston, $T X$, United States, ${ }^{2}$ Center for Translational Research on \\ Inflammatory Diseases (CTRID), Michael E. DeBakey Department of Veterans Affairs, Houston, TX, United States, \\ ${ }^{3}$ Department of Pathology and Immunology, Baylor College of Medicine, Houston, TX, United States, ${ }^{4}$ Biology of \\ Inflammation Center, Baylor College of Medicine, Houston, TX, United States
}

OPEN ACCESS

Edited by:

Humam Kadara

University of Texas MD Anderson Cancer Center, United States

Reviewed by:

Seon Hee Chang,

University of Texas MD Anderson

Cancer Center, United States Nejat K. Egilmez,

University of Louisville, United States

*Correspondence:

Farrah Kheradmand

farrahk@bcm.edu

tThese authors have contributed equally to this work

Specialty section:

This article was submitted to Cancer Immunity and Immunotherapy,

a section of the journal

Frontiers in Oncology

Received: 09 September 2019 Accepted: 22 November 2019

Published: 10 December 2019

Citation:

Armstrong D, Chang C-Y, Lazarus DR,

Corry D and Kheradmand F (2019)

Lung Cancer Heterogeneity in

Modulation of Th17/IL17A

Responses. Front. Oncol. 9:1384.

doi: 10.3389/fonc.2019.01384
The interplay between tumors and their immune microenvironment is critical for cancer development and progression. The discovery of tumor heterogeneity has provided a window into a complex interplay between tumors, their secreted products, and host immune responses at the cellular and molecular levels. Tumor heterogeneity can also act as a driving force in promoting treatment resistance and correlates with distinct tumor-mediated acquired immune responses. A prevailing question is how genetic aberrations in solid tumors can shape the immune landscape, resulting in pro-tumor or anti-tumor activities. Here we review evidence for clinical and pathophysiological mechanisms that underlie different types of non-small cell lung cancer (NSCLC) and provide new insights for future immunomodulatory-based therapies. Some of the more common driver mutations in NSCLC heterogeneity includes the opposing immune responses in oncogenic mutations in $K$-ras vs. non-K-ras models and their pro-inflammatory cytokines such as interleukin (IL)17A. We will discuss possible molecular and metabolic mechanisms that may govern the opposing immune responses observed in distinct genetic models of NSCLCs. A deeper understanding of how tumor heterogeneity modulates immune response can improve current therapeutic strategies and provide precise treatment to individual lung cancer patients.

Keywords: tumor heterogeneity, lung cancer, immune landscape, tumor microenvironment, immunotherapy, Th17, IL17A

\section{INTRODUCTION}

Lung cancer is the leading cause of cancer-associated deaths, and its predominant histological presentation (e.g., adeno- and squamous-carcinoma) are collectively referred to as non-small cell lung cancers (NSCLCs) (1). Several mutations have been discovered in association with NSCLC development, and are used to characterize high interpatient heterogeneity (2). The tumor microenvironment is also highly heterogeneous because it includes different mutated cancer cells, and a diverse array of immune cells collected in and around solid tumors (3). Paradoxically, immune cells in the tumor microenvironment can promote tumor survival or destroy transformed cells, providing both pro- or anti-tumor responses, respectively (3). Mediators of these processes include cytokines, chemokines, metabolites, and checkpoint ligands. Thus, the immune cell milieu and the tumor microenvironment plays a vital role to eliminate tumor cells. Tumor cells that manage to escape the immune surveillance propagate and invade the surrounding tissue. Adaptive immune cell infiltration has been described in several type of solid tumors, including T helper 17 
(Th17) cells (4), a subset of CD4 ${ }^{+}$cells which secrete IL17A. Th17 cells are recruited to tumor sites and inflammatory sites by $\mathrm{C}-\mathrm{C}$ motif chemokine ligand 20 (CCL20) expressed by epithelial and stromal cells, interacting with C-C Chemokine receptor type 6 (CCR6) on Th17 cells $(5,6)$. The role of Th17 cells in promoting or inhibiting various human cancers seems to be contextdependent $(7,8)$. The influence of environmental cues may be one of the major determinants to modulate Th17 cell recruitment and function. Recently, growing evidence indicates that tumorintrinsic genetics determine the corresponding immune profile. To further understand how tumor mutations impact Th17/IL17A response, we review the role of this response in human tumors as well as the studies in K-ras vs. non-K-ras driven NSCLC (9-11). We also discuss immunotherapies and offer possible molecular and metabolic mechanisms that modulate Th17 cells in tumors.

\section{ASSOCIATION BETWEEN Th17/IL17A IN HUMAN TUMORS}

\section{Pro-Tumor Effect of IL17A}

Chronic inflammation is one of the hallmarks of malignant transformations (3). Induction of IL17A to various inflammatory conditions promotes the recruitment of innate immune cells such as neutrophils, and macrophages (12). Cigarette smoking which is associated with over $80 \%$ of all lung cancers, recruits Th17 cells in the lungs $(13,14)$, and has been associated with poor survival in NSCLC patients (15). Serum IL17A level is positively linked to vascular endothelial growth factor (VEGF) concentration in NSCLC patients, suggesting IL17A may promote angiogenesis in the tumor (16). Further, patients with high serum IL17A concentrations demonstrated a shorter overall survival rate compared with those with low levels (17). High IL17A levels also correlated with increased lymph node invasion, and distant metastases in NSCLC (17). Several meta-analyses have shown that high IL17A expression prognosticated poorer survival outcome or late stage diagnosis in NSCLC patients (18-20). Th17 cell infiltration also positively correlated to poor prognostic outcome in several other types of cancer, including colon, gastric, and liver. In contrast, Th17 cell infiltration in ovarian cancer has been shown to associate with better survival (21), while in nasopharyngeal cancer patients there was no significant association between tumor-infiltrating Th17 cells and survival, indicating a specific role for Th17 cells based on the specific tumor (22).

In addition to Th17 cells and association with tumor survival, chemokines and their receptors related to trafficking of this T cell subset have also been examined in NSCLC. For instance, high expression of CCR6, a chemokine receptor expressed by Th17 cells (23), was associated with shorter disease-free survival in NSCLC patients. Similarly, CCL20, the only chemokine known to interact with CCR6 (24), was elevated in the tumor compared to tumor-free adjacent lung tissue (25). Together, these findings suggest that the CCL20/CCR6 axis might facilitate infiltration of Th17 cell in NSCLC and promote tumor progression (25).

In addition to IL17A, Th17 cells can also secrete other cytokines, including IL-22 (26). Although elevated IL-22 expression has been detected in the primary lung tumor, serum, and malignant pleural effusion in patients $(27,28)$, its expression did not correlate with prognostic outcome in smokers with NSCLC (27). Further, IL-23, another cytokine that is secreted by myeloid cells and can polarize naive $\mathrm{CD} 4^{+} \mathrm{T}$ cells to Th17 cells $(29,30)$, was found to be elevated in the serum of lung cancer patients compared with healthy controls (31). Similarly, however, there is no known correlation between IL-23 expression and NSCLC prognosis to date.

\section{Anti-tumor Effect of IL17A}

Multiple lines of evidence suggest that IL17A/Th17 may play a pro-tumorigenic role as an increased number of Th17 cells are found in human colorectal (32), gastric (33), hepatocellular (34), and lung cancers (35). However, despite the aforementionedassociation studies, recent evidence also suggests the possibility for an immuno-protective role of Th17 cells in tumors. Different subsets of TILs in NSCLC can produce IL17A, such as natural killer, natural killer $\mathrm{T}$ cells, and $\gamma \delta \mathrm{T}$ cells (36) but $\mathrm{CD}^{+}$ stem cell-like memory $\mathrm{T}$ cells showed the highest expression of this cytokine (37). Since Th17 cells could transdifferentiate into interferon-gamma (IFN- $\gamma$ )-secreting Th1 cells $(38,39)$, increased Th17 cells infiltrate into the tumor may promote tumor regression. In support of this concept, induction of Th17 cells to IFN- $\gamma$-secreting Th 1 cells and differentiation into a durable stem memory phenotype enhances long-term anti-tumor responses $(37,40)$, and this feature has been applied in adoptive $\mathrm{T}$ cell transfer therapy in a murine preclinical model (41).

Targeting Th17 or IL17A pathways as a treatment for cancer has not yet been reported in clinical trials; however, two recent reports suggest their important role in anti-tumor activity. In one case, humanized monoclonal anti-IL17 treatment of psoriatic lesions in a patient with colon cancer was associated with cancer relapse after initial successful therapy with anti-programmed cell death protein 1 (PD-1) (42), though it is not clear whether this patient would have relapsed without the depletion of IL17A. Another case showed that anti-PD-1 treatment in patients with melanoma increased Th17 cell numbers in responders compared to non-responders (43). Although the role of Th17 cells in checkpoint blockade treatments remains unknown, these clinical reports highlight a potential anti-tumor effect of Th17 cells in immune-targeted therapy.

\section{GENETIC DETERMINANTS OF Th17 RESPONSE}

Th17 cells have been shown to have both pro- and antitumor effects. Their action depends on the intrinsic and extrinsic phenotypes of the tumor milieu. Given that Th17 cells express other factors, one explanation for the opposing roles of Th17 cells in different cancer genomics may be their cellular heterogeneity. The different tumor genetics may also induce different subsets or phenotypes of Th17 cells that leads to their pro- or anti-tumor roles. Studies have shown that IL-23 induces TGF $\beta 3$ rather than TGF $\beta 1$, which combined with IL-6 leads to development of pathogenic Th17 cells, 
which are both functionally and transcriptionally distinct from homeostatic, non-pathogenic Th17 cells induced by TGF $\beta 1$, as shown in experimental autoimmune encephalitis models $(44,45)$. Additionally, there are other microenvironmental factors, such as specific microbial species in the intestine, that have been shown to induce pathogenic Th17 cells (46), whereas commensal bacteria can maintain homeostatic, protective Th17 cells in the gut $(46,47)$. Thus, there may be other inducers of pathogenic or homeostatic Th17 cells at work in these lung tumor models, perhaps through secreted cytokines by the tumor cells. However, more research is necessary to elucidate which types of Th17 cells are present in each of these models and to understand different subtypes of Th17 in different conditions as well as their role in cancer progression.

Emerging evidence indicates that the cancer cell-intrinsic aberration determines the immune landscape of tumors (48, 49). For example, the high mutational burden in tumors such as melanoma and NSCLC display increased $\mathrm{T}$ cell influx, which is associated with the beneficial outcome of checkpoint blockade treatments $(50,51)$. Importantly, six distinct immune subtypes have been mapped in multiple tumor types indicating that specific driver mutations dictate unique tumor microenvironments (52). Oncogenes and tumor suppressor mutations drive alterations in cancer which can metabolically modulate leukocyte function, polarization, and recruitment in the microenvironment $(53,54)$. Th17 cells can be generated under activation of oncogene or inhibition of tumor suppressors in both human and murine models (9-11). Oncogenic-driven NSCLC models have predominantly shown a pro-tumorigenic role of IL17A responses $(9,10)$, whereas IL17A regulation in a loss of tumor suppressor NSCLC model has been associated with an anti-tumorigenic function (11).

The underlying genetics of tumors can elicit the type of immune response, as shown in both the clinic and in preclinical models. Furthermore, the same immune milieu (e.g., TILs abundant in Th17 cells), may have opposing effects on tumor establishment and or progression. An example of this dichotomous response to IL17A has been shown in K-ras vs. non$K$-ras models of NSCLC, where IL17A was shown to promote growth in $K$-ras-driven tumors (10), but IL17A were required to inhibit early oncogenesis in a non-K-ras driven model (11). Specifically, mice with airway specific deletion of Phosphatase and tensin homolog (Pten) and SMAD family member $4\left(\mathrm{Pts}^{d / d}\right)$ spontaneously develop NSCLC by 9 months of age (55); global deficiency of $I l 17 a$ resulted in earlier and increased metastasis which could be rescued with adoptive transfer of IL17a-sufficient CD4 ${ }^{+}$T cells (11).

Th17 cell-derived cytokines can regulate stromal cells in the tumor microenvironment. IL17A promotes myeloid cell recruitment, which can suppress tumor immunity. K-ras mutations in alveolar epithelial cells express high levels of $\mathrm{C}-\mathrm{X}-\mathrm{C}$ motif chemokine receptor 2 (CXCR2) ligands, which recruit inflammatory and endothelial cells (56). Further, $K$ ras mutations can induce Granulocyte-macrophage colonystimulating factor (GM-CSF) expression, which in turn recruits

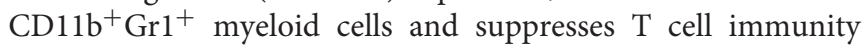
in tumors (57). In a K-ras-driven model, an oncogenic form of $K$-ras expressed in the club cells (CCSP $P^{\text {cre }} / K$-ras $\left.{ }^{G 12 D}\right)$, Th17 cells and $\mathrm{T}$ regulatory cells (Tregs), but not Th1 cells, were recruited to the tumor tissue (9). A mouse model of $\mathrm{K}$-ras ${ }^{G 12 D}$ pancreatic cancer showed similar infiltration of IL17A producing cells (58). When $C C S P^{\text {cre }} / K$-ras ${ }^{G 12 D}$ were induced with Chronic Obstructive Pulmonary Disease (COPD)-like inflammation, local production of IL17A recruited $\mathrm{Gr}^{+}{ }^{+} \mathrm{CD} 11 \mathrm{~b}^{+}$myeloid cells to the lung. Il17a deficient (CCSP $P^{\text {cre }} / \mathrm{K}_{\text {-ras }}{ }^{G 12 D} ; I l 17 a^{-/-}$) conferred decreased tumor progression, angiogenesis, pro-inflammatory

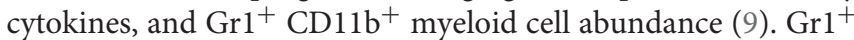
$\mathrm{CD}_{11 \mathrm{~b}^{+}}$myeloid cells, also known as myeloid derived suppressor cells (MDSCs), can inhibit the anti-tumor activity of $\mathrm{CD}^{+} \mathrm{T}$ cells. However, $\mathrm{CD}^{+} \mathrm{T}$ cells depletion did not restore the tumor growth in both IL17A sufficient and deficient conditions (9), suggesting $\mathrm{Gr}^{+} \mathrm{CD}^{+} \mathrm{b}^{+}$myeloid cell can directly promote tumor growth. This concept is confirmed by depletion of $\mathrm{Gr}^{+}$ $\mathrm{CD}_{11 \mathrm{~b}}{ }^{+}$cells in $\mathrm{CCSP}^{\text {cre }} / K$-ras ${ }^{G 12 D}$, resulting in reduced tumor progression (9). Similarly, IL17A depletion showed decreased $\mathrm{CD}_{11 b^{+}} \mathrm{Gr}^{+}$myeloid cells and metastasis in an oncogenedriven breast cancer model (59). IL17A-mediated induction of IL-6 and Granulocyte-colony stimulating factor (G-CSF) expression in the tumor cells has been shown to recruit tumorassociated neutrophils (Ly-6G ${ }^{+}$) (10). Blocking IL-6 or Ly-6G showed reduced tumor burden than anti-PD-1 treatment in high IL17A lung tumors (10). Additionally, IL17A has been shown to promote metastasis in a pre-clinical model using $\mathrm{K}$-ras-driven NSCLC cell line, a process that was shown to be driven through IL-6 signaling $(60,61)$. Together, the findings in $K$-ras models indicate that IL17A is a pro-tumorigenic factor $(9,62)$.

In contrast to cancer-promoting effects of IL17A described above, IL17A has been shown to repress tumor development. In a non-K-ras model of NSCLC model Pts $4^{d / d}$ (55), Th17 cell infiltrated the lungs before- and in early-stages of NSCLC (11). Immune competent Pts $4^{d / d}$ mice lacking $I 117 a$ showed accelerated tumor progression and metastasis, indicating that IL17A plays a beneficial role in anti-tumor responses (11). Consistently, Th17 cells were also found in TILs in patients with early-stage NSCLC (11). In the Pts $4^{d / d}$ model, there is an increase in Th17 cell infiltration, both before and after tumor development; however, after tumor development, there is an additional increase in the relative abundance of exhausted PD$1^{+} \mathrm{T}$ cells and cytotoxic $\mathrm{T}$ lymphocytes (CTLs) in addition to increased Th17 cells. Furthermore, a decrease in Th17 cells and an increase in PD-1 ${ }^{+} \mathrm{T}$ cells have been found in the mediastinal lymph nodes in both NSCLC patients and $P t s 4^{d / d}$ mice (11). The expression of pro-inflammatory molecules in the $P t s 4^{d / d}$ model has not been reported. Strikingly, in contrast to the $K$-ras model (9), the $P t s 4^{d / d}$ model with $I l 17 a^{-/-}$, shows increased tumor burden and metastasis (11). Anti-tumor effects of Th17 cells found in NSCLC were also reported in the B16 melanoma model. When tumor-specific Th17 cells were adoptively transferred into the host, they induced activation of tumor-specific $\mathrm{CD}^{+} \mathrm{T}$ cell for anti-tumor effects (63). Assessment of metastases in this model revealed fewer infiltrating CTL and Th1 in metastatic sites of $I l 17 a^{-/-}$compared with Th17-sufficient mice, indicating that IL17A is required for efficient immune cell infiltration into metastatic sites (63). Both the B16 melanoma and Pts $4^{d / d}$ 
NSCLC models show that anti-tumor immunity mediated by IL17A is enhanced by the recruitment of dendritic cells (DCs). IL17A can recruit $\mathrm{CD}_{103^{+}}$DCs which are critical for the anti-tumor function of $\mathrm{CD}^{+} \mathrm{T}$ cell in $\mathrm{Pts} 4^{d / d}$ mice (11). In vitro experiments also demonstrated that IL17A directly inhibits $\mathrm{CD}^{2} 26^{+}$differentiation of bone marrow-derived macrophages $(\mathrm{BMDM})$ and suppresses the expression of inhibitory mediators Arginase-1 and Vegf. IL17A increases inducible (i) $\mathrm{CD}_{103}{ }^{+}$ DC migration in a dose-dependent manner and promotes the upregulation of the co-stimulatory molecule CD86 (11). Th17 cells have also been shown to promote the recruitment of CD8 $\alpha^{+}$ DCs in the tumor tissues in the B16 melanoma model (63). Notably, CD103 ${ }^{+}$DC counts were significantly fewer in the above mentioned constitutive IL17A expressed $K$-ras than $K$-ras only lung cancer model (10). Decreased CD103 ${ }^{+}$DC in both constitutive IL17A expressed K-ras and IL17A deleted Pts $4^{d / d}$ models showed enhanced NSCLC progression (Figure 1). These findings further support the significance of genetic aberration in tumors that can result in a differential role for Th17 cells in NSCLC; whether and how these findings relate to immune response in other genetic mutations in cancer remains unknown. Furthermore, it remains unclear which subsets Th17 cells play pro or anti-tumor effects, and as such, this unmet need provides a new area of onco-immunity that should be explored in the future.

Cytokine milieu is not the only way to polarize Th17 cells, as metabolites are also critical for determining the cellular function and fate of immune cells $(64,65)$. The opposing immune responses observed in these distinct genetic models may be in part due to metabolism. Metabolic reprogramming in cancer impacts recruitment and polarization of immune cells $(66,67)$.

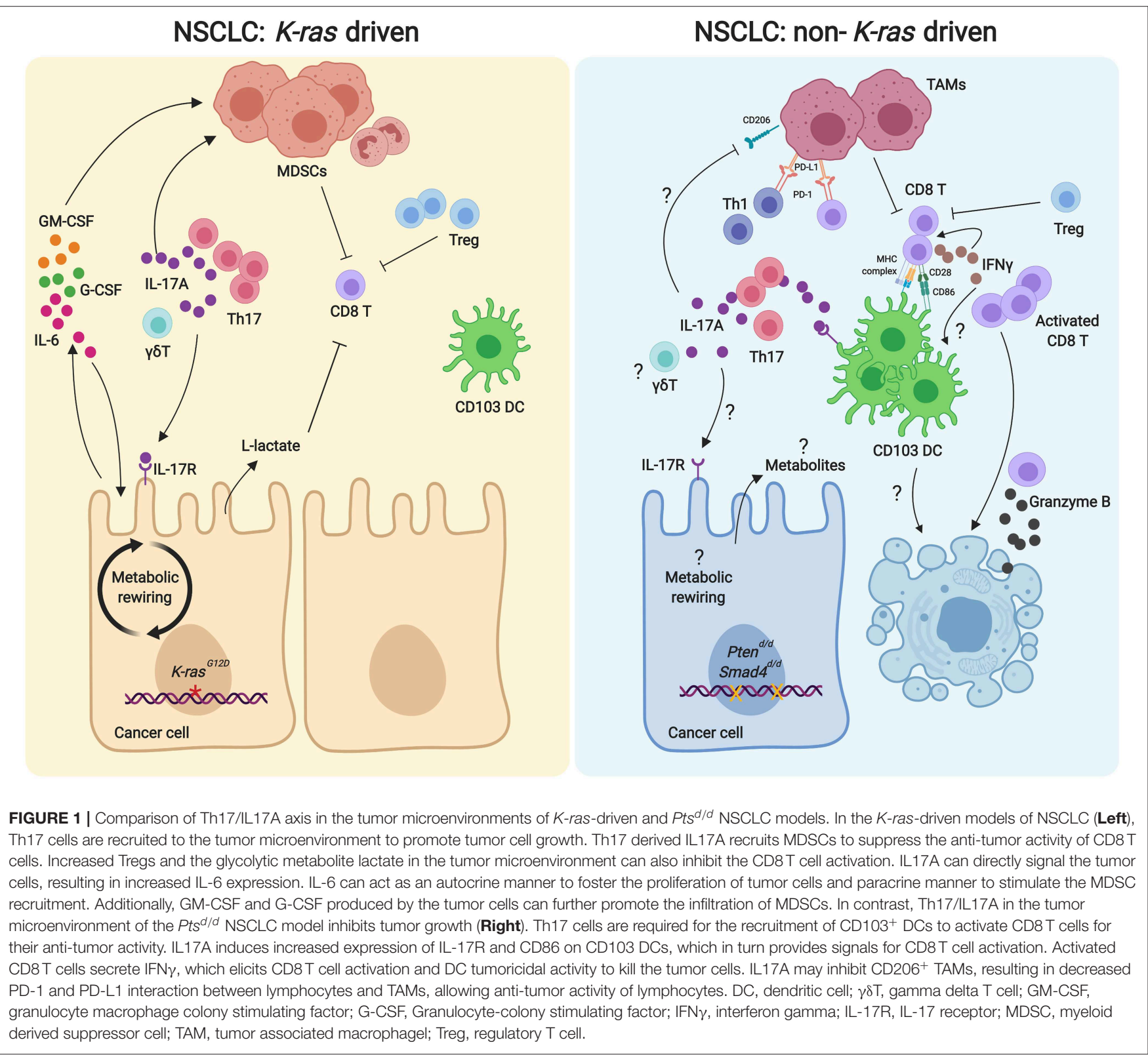


The interaction between tumor cells and the surrounding stromal cells is known to be involved in cancer development and progression (66). Nutrient competition and nutrient symbiosis in the tumor microenvironment support tumor growth and attenuate anti-tumor immunity (68). Cell intrinsic genetic variables can contribute to metabolic heterogeneity in the tumor microenvironment. For example, recent findings that focused on metabolic properties of $K$-ras mutation cancer cells have shown enhanced nutrient uptake and rewiring of their metabolism (69, $70)$. Increased glycolysis was observed in $\mathrm{K}$-ras NSCLC patients and a murine model $(69,71)$. Lactate, a product of glycolysis, is sensed by $\mathrm{CD}^{+} \mathrm{T}$ cells, disturbing their metabolism and function, resulting in decreased cell proliferation and IFN- $\gamma$ expression (72). Extracellular sodium lactate can induce Th17 differentiation and IL17A expression (73). Glutamine is also a well-known nutrient for cells with high mitotic index and a potential target for cancer therapy (74). Activation of glutamine metabolism (i.e., via glutaminase) has been shown to alter chromatin and promote Th17 cell differentiation, but it constrain Th1 and CTL development (75). Future studies are needed to understand the development and the role of $\mathrm{T}$ cell subsets in the glutamine restricted NSCLC models. By understanding the metabolic reprogramming of cancer cells and how this metabolic shift promotes immune evasion, we can target this interaction and re-energize the anti-tumor immunity to fight cancer.

\section{IMMUNOTHERAPY AND Th17 RESPONSE IN CANCER}

Although an opposing role of Th17 and IL17A responses in cancer development is becoming evident, accumulating data from mouse studies suggest that Th17 cells can cause more significant tumor regression compared with Th1 cells $(63,76-$ 78). Adoptive transfer of tumor-specific Th17 cells can mediate destruction of $\mathrm{B} 16$ melanoma and elicit IFN- $\gamma$ production (76). Similarly, adoptive transfer of antigen-specific Th17 cells promoted $\mathrm{CD} 8^{+} \mathrm{T}$ cell activation in vivo (63). Chimeric antigen receptors (CAR)-T cells, adoptive transfer of ICOS stimulated Th17 cells, instead of CD28 stimulated Th17 cells, resulted in a robust anti-tumor activity, when compared with ICOS stimulated $\mathrm{CD}^{+} \mathrm{T}$ cells (78). These findings indicate that adoptive transfer of Th17 cells has potent anti-tumor activities. However, the exact mechanism of how adoptive transferred Th17 cells have this strong effect of activating $\mathrm{CD}^{+} \mathrm{T}$ cells and the intrinsic and extrinsic stimuli that lead to this phenotype are not clear.

Adoptive T cell therapy (ACT) has shown some efficacy in several types of cancer; however, only $25 \%$ of patients achieve durable and complete tumor regression (79). Tumor glycolysis has been associated with immune resistance to ACT where overexpression of glycolytic molecules hampered T cell-mediated killing of tumor cells (80). Tumor intrinsic genetic mutations, (e.g., PTEN), are the driver to promote tumor glycolysis. In clinical samples, increased glycolysis is associated with decreased $\mathrm{T}$ cell infiltration in melanoma and NSCLC (80), suggesting that ACT co-treated with glycolysis inhibitors may enhance the therapeutic outcome for patients. As activation of glycolysis is essential for Th17 cell development (81), investigating the efficacy of glycolysis inhibitors co-treated with Th17-based adoptive T cell therapy is critical.

Additionally, Th17 cells have stem-cell like properties which make them an ideal cell type for CAR-T cell therapy $(40,77)$. Although human Th17 cells express terminal differentiation markers, these cells have anti-tumor activity and long-lived in vivo. Furthermore, Th17 cells can self-renew and differentiate into other T helper subsets. For example, under Th1 polarizing conditions, a significant fraction of Th17 cells express IFN- $\gamma(40$, 77). In vivo, Foxp $3^{+} \mathrm{IL}-17^{+} \mathrm{CD} 4^{+}$and IFN- $\gamma^{+} \mathrm{IL}-17^{+} \mathrm{CD} 4^{+} \mathrm{T}$ cells are present (40). Upon adoptive transfer, Th17 cells converted to Th1-like cells and produced IFN- $\gamma$, which is critical for anti-tumor effects $(40,77)$.

There are several concerns with targeting Th17 response in cancer, one of which is the concomitant development of Th17 cells and Tregs in cancer. The differentiation of Th17 cells is dependent on the relative expression of IL- 6 and TGF$\beta$ (82). However, IL-6 inhibits Treg development (83). An appropriate balance between Th17 cells and Tregs is critical in regulating inflammation and promoting tumor immune surveillance $(39,82)$. Considering this delicate equilibrium between Tregs and Th17 cells in cancer, targeting Th17 cells alone may enhance the development of Tregs, and therefore suppresses antitumor activities. Targeting Th17 cell-mediated tumor-promoting inflammation and Treg-mediated immune suppression simultaneously could be an alternative way to provide effective immunotherapy in solid tumors. Checkpoint blockades that dampen active tumor immunity combined with anti-Th17 agents is another possible route to explore. However, the premise of this dual treatment is that Th17 and IL-17 responses are tumor-promoting not tumor-suppressive, which could be problematic considering the case reports mentioned above, and pre-clinical models. Therefore, while the exact mechanism(s) of immune and specific tumor responses require an individualized assessment of genes and its microenvironment, combined effects of oncogenic changes and adaptive immune therapy (e.g., Th17 cells) is an exciting consideration for near future treatment in NSCLC.

\section{Prospective}

The summation of evidence reveals there are opposing roles for Th17 cells in different genetic drivers of cancer, though there are still some essential remaining knowledge gaps. It appears that different cancers respond distinctly to similar immune contextures. Mouse models thus far have been limited in the genetic mutations and investigation of their corresponding immune responses. Furthermore, clinical observations need to be extended to clinical studies. Future human NSCLC studies are needed to assess the immune infiltrates with different oncogenic foci. Further, how different cancers respond to, or whether tumors are reinforced or inhibited by various immune contextures, should be investigated using new sequencing techniques, and through immunogenomics of tumor samples (84-86). Genetic sequencing, mass spectrometry, and other high throughput methods can provide genetic mutation of tumor cells and 
the corresponding immune setting in its microenvironment (85). Therapeutically, immunogenomics is an approach to identify neo-antigens for vaccination and $\mathrm{T}$ cell therapy (85, 86). Determining how genetic alterations specifically affect the immune system will open up more opportunities for immunotherapy and personalized medicine. For an exploration of immunotherapy, it may be beneficial to further investigate the potential of Th17 cells in CAR-T cell therapy. Given the findings in murine models, knowing the underlying genetics of a patient's tumor may inform whether enhancing or dampening a Th17 response would improve outcomes for patients in personalized medicine.

\section{AUTHOR CONTRIBUTIONS}

DA and C-YC: equal contribution to conception of the work, drafting the work, final approval of version to be published, and agreement to be accountable for all aspects of the work. FK,

\section{REFERENCES}

1. Molina JR, Yang P, Cassivi SD, Schild SE, Adjei AA. Non-small cell lung cancer: epidemiology, risk factors, treatment, and survivorship. Mayo Clin Proc. (2008) 83:584-94. doi: 10.1016/S0025-6196(11)60735-0

2. Sakashita S, Sakashita M, Sound Tsao M. Genes and pathology of non-small cell lung carcinoma. Semin Oncol. (2014) 41:28-39. doi: 10.1053/j.seminoncol.2013.12.008

3. Hanahan D, Weinberg RA. Hallmarks of cancer: the next generation. Cell. (2011) 144:646-74. doi: 10.1016/j.cell.2011.02.013

4. Su X, Ye J, Hsueh EC, Zhang Y, Hoft DF, Peng G. Tumor microenvironments direct the recruitment and expansion of human Th17 cells. J Immunol. (2010) 184:1630-41. doi: 10.4049/jimmunol.0902813

5. Yu Q, Lou XM, He Y. Preferential recruitment of Th17 cells to cervical cancer via CCR6-CCL20 pathway. PLoS ONE. (2015) 10:e0120855. doi: 10.1371/journal.pone.0120855

6. Hirata T, Osuga Y, Takamura M, Kodama A, Hirota Y, Koga K, et al. Recruitment of CCR6-expressing Th17 cells by CCL 20 secreted from IL1 beta-, TNF-alpha-, and IL-17A-stimulated endometriotic stromal cells. Endocrinology. (2010) 151:5468-76. doi: 10.1210/en.2010-0398

7. Wilke CM, Kryczek I, Wei S, Zhao E, Wu K, Wang G, et al. Th17 cells in cancer: help or hindrance? Carcinogenesis. (2011) 32:643-9. doi: 10.1093/carcin/bgr019

8. Chang SH. T helper 17 (Th17) cells and interleukin-17 (IL-17) in cancer. Arch Pharm Res. (2019) 42:549-59. doi: 10.1007/s12272-019-01146-9

9. Chang SH, Mirabolfathinejad SG, Katta H, Cumpian AM, Gong L, Caetano MS, et al. T helper 17 cells play a critical pathogenic role in lung cancer. Proc Natl Acad Sci USA. (2014) 111:5664-9. doi: 10.1073/pnas.1319051111

10. Akbay EA, Koyama S, Liu Y, Dries R, Bufe LE, Silkes M, et al. Interleukin17A promotes lung tumor progression through neutrophil attraction to tumor sites and mediating resistance to PD-1 blockade. J Thorac Oncol. (2017) 12:1268-79. doi: 10.1016/j.jtho.2017.04.017

11. You R, DeMayo FJ, Liu J, Cho SN, Burt BM, Creighton CJ, et al. IL17A regulates tumor latency and metastasis in lung adeno and squamous SQ.2b and AD.1 cancer. Cancer Immunol Res. (2018) 6:645-57. doi: 10.1158/2326-6066.CIR-17-0554

12. Roussel L, Houle F, Chan C, Yao Y, Berube J, Olivenstein R, et al. IL-17 promotes p38 MAPK-dependent endothelial activation enhancing neutrophil recruitment to sites of inflammation. J Immunol. (2010) 184:45317. doi: 10.4049/jimmunol.0903162

13. Shan M, Cheng HF, Song LZ, Roberts L, Green L, Hacken-Bitar $\mathrm{J}$, et al. Lung myeloid dendritic cells coordinately induce $\mathrm{TH} 1$ and
DC, and DL: revised and edited the concepts and writing of the manuscript.

\section{FUNDING}

This work was supported by NIH grants R01ES029442-01 and R01 AI135803-01, VA Merit grant CX000104 to FK, and DC NIOSH, Southwest Center for Occupational and Environmental Health, Pilot Projects Research Training Award-T42 and Baylor College of Medicine Comprehensive Cancer Training ProgramCPRIT RP160283 to C-YC, and the National Institute of General Medical Sciences of the NIH under award number T32GM088129 to DA.

\section{ACKNOWLEDGMENTS}

We acknowledge the contributions of Dr. Ran You, that aided the efforts of the authors.
TH17 responses in human emphysema. Sci Transl Med. (2009) 1:4ra10. doi: 10.1126/scitranlsmed.3000154

14. Shan M, Yuan X, Song LZ, Roberts L, Zarinkamar N, Seryshev A, et al. Cigarette smoke induction of osteopontin (SPP1) mediates $\mathrm{T}(\mathrm{H}) 17$ inflammation in human and experimental emphysema. Sci Transl Med. (2012) 4:117ra9. doi: 10.1126/scitranslmed.3003041

15. Chen X, Wan J, Liu J, Xie W, Diao X, Xu J, et al. Increased IL-17-producing cells correlate with poor survival and lymphangiogenesis in NSCLC patients. Lung Cancer. (2010) 69:348-54. doi: 10.1016/j.lungcan.2009.11.013

16. Pan B, Che D, Cao J, Shen J, Jin S, Zhou Y, et al. Interleukin-17 levels correlate with poor prognosis and vascular endothelial growth factor concentration in the serum of patients with non-small cell lung cancer. Biomarkers. (2015) 20:232-9. doi: 10.3109/1354750X.2015.1068853

17. Xu C, Hao K, Yu L, Zhang X. Serum interleukin-17 as a diagnostic and prognostic marker for non-small cell lung cancer. Biomarkers. (2014) 19:28790. doi: 10.3109/1354750X.2014.908954

18. Zhang X, Weng W, Xu W, Wang Y, Yu W, Tang X, et al. Prognostic significance of interleukin 17 in cancer: a meta-analysis. Int J Clin Exp Med. (2014) 7:3258-69.

19. Zeng Y, Zhang Q, Wang H, Lu M, Kong H, Zhang Y, et al. Prognostic significance of interleukin-17 in solid tumors: a meta-analysis. Int J Clin Exp Med. (2015) 8:10515-36.

20. Wang XF, Zhu YT, Wang JJ, Zeng DX, Mu CY, Chen YB, et al. The prognostic value of interleukin-17 in lung cancer: a systematic review with meta-analysis based on Chinese patients. PLoS ONE. (2017) 12:e0185168. doi: 10.1371/journal.pone.0185168

21. Kryczek I, Banerjee M, Cheng P, Vatan L, Szeliga W, Wei S, et al. Phenotype, distribution, generation, and functional and clinical relevance of Th17 cells in the human tumor environments. Blood. (2009) 114:1141-9. doi: 10.1182/blood-2009-03-208249

22. Zhang YL, Li J, Mo HY, Qiu F, Zheng LM, Qian CN, et al. Different subsets of tumor infiltrating lymphocytes correlate with NPC progression in different ways. Mol Cancer. (2010) 9:4. doi: 10.1186/1476-4598-9-4

23. Singh SP, Zhang HH, Foley JF, Hedrick MN, Farber JM. Human T cells that are able to produce IL-17 express the chemokine receptor CCR6. J Immunol. (2008) 180:214-21. doi: 10.4049/jimmunol.180.1.214

24. Schutyser E, Struyf S, Van Damme J. The CC chemokine CCL20 and its receptor CCR6. Cytokine Growth Factor Rev. (2003) 14:409-26. doi: 10.1016/S1359-6101(03)00049-2

25. Kirshberg S, Izhar U, Amir G, Demma J, Vernea F, Beider K, et al. Involvement of CCR6/CCL20/IL-17 axis in NSCLC disease progression. PLoS ONE. (2011) 6:e24856. doi: 10.1371/journal.pone.0024856 
26. Zenewicz LA, Yancopoulos GD, Valenzuela DM, Murphy AJ, Stevens $\mathrm{S}$, Flavell RA. Innate and adaptive interleukin-22 protects mice from inflammatory bowel disease. Immunity. (2008) 29:947-57. doi: 10.1016/j.immuni.2008.11.003

27. Kobold S, Volk S, Clauditz T, Kupper NJ, Minner S, Tufman A, et al. Interleukin-22 is frequently expressed in small- and large-cell lung cancer and promotes growth in chemotherapy-resistant cancer cells. J Thorac Oncol. (2013) 8:1032-42. doi: 10.1097/JTO.0b013e31829923c8

28. Ye ZJ, Zhou Q, Yin W, Yuan ML, Yang WB, Xiang F, et al. Interleukin 22producing CD4+ T cells in malignant pleural effusion. Cancer Lett. (2012) 326:23-32. doi: 10.1016/j.canlet.2012.07.013

29. Wang K, Karin M. The IL-23 to IL-17 cascade inflammation-related cancers. Clin Exp Rheumatol. (2015) 33(4 Suppl 92):S87-90.

30. Iwakura Y, Ishigame H. The IL-23/IL-17 axis in inflammation. J Clin Invest. (2006) 116:1218-22. doi: 10.1172/JCI28508

31. Cam C, Karagoz B, Muftuoglu T, Bigi O, Emirzeoglu L, Celik S, et al. The inflammatory cytokine interleukin- 23 is elevated in lung cancer, particularly small cell type. Contemp Oncol (Pozn). (2016) 20:215-9. doi: 10.5114/wo.2016.61562

32. Tosolini M, Kirilovsky A, Mlecnik B, Fredriksen T, Mauger S, Bindea G, et al. Clinical impact of different classes of infiltrating $\mathrm{T}$ cytotoxic and helper cells (Th1, th2, treg, th17) in patients with colorectal cancer. Cancer Res. (2011) 71:1263-71. doi: 10.1158/0008-5472.CAN-10-2907

33. Yamada Y, Saito H, Ikeguchi M. Prevalence and clinical relevance of Th17 cells in patients with gastric cancer. J Surg Res. (2012) 178:685-91. doi: 10.1016/j.jss.2012.07.055

34. Zhang JP, Yan J, Xu J, Pang XH, Chen MS, Li L, et al. Increased intratumoral IL-17-producing cells correlate with poor survival in hepatocellular carcinoma patients. J Hepatol. (2009) 50:980-9. doi: 10.1016/j.jhep.2008.12.033

35. Li Y, Cao ZY, Sun B, Wang GY, Fu Z, Liu YM, et al. Effects of IL-17A on the occurrence of lung adenocarcinoma. Cancer Biol Ther. (2011) 12:610-6. doi: $10.4161 /$ cbt.12.7.16302

36. Jin W, Dong C. IL-17 cytokines in immunity and inflammation. Emerg Microbes Infect. (2013) 2:e60. doi: 10.1038/emi.2013.58

37. Sheng SY, Gu Y, Lu CG, Tang YY, Zou JY, Zhang YQ, et al. The characteristics of naive-like $\mathrm{T}$ cells in tumor-infiltrating lymphocytes from human lung cancer. J Immunother. (2017) 40:1-10. doi: 10.1097/CJI.0000000000000147

38. Harbour SN, Maynard CL, Zindl CL, Schoeb TR, Weaver CT. Th17 cells give rise to Th1 cells that are required for the pathogenesis of colitis. Proc Natl Acad Sci USA. (2015) 112:7061-6. doi: 10.1073/pnas.1415675112

39. Guery L, Hugues S. Th17 cell plasticity and functions in cancer immunity. Biomed Res Int. (2015) 2015:314620. doi: 10.1155/2015/314620

40. Kryczek I, Zhao E, Liu Y, Wang Y, Vatan L, Szeliga W, et al. Human TH17 cells are long-lived effector memory cells. Sci Transl Med. (2011) 3:104ra0. doi: 10.1126/scitranslmed.3002949

41. Guedan S, Chen X, Madar A, Carpenito C, McGettigan SE, Frigault MJ, et al. ICOS-based chimeric antigen receptors program bipolar TH17/TH1 cells. Blood. (2014) 124:1070-80. doi: 10.1182/blood-2013-10-535245

42. Esfahani K, Miller WH Jr. Reversal of autoimmune toxicity and loss of tumor response by interleukin-17 blockade. $N$ Engl J Med. (2017) 376:1989-91. doi: 10.1056/NEJMc1703047

43. Krieg C, Nowicka M, Guglietta S, Schindler S, Hartmann FJ, Weber LM, et al. High-dimensional single-cell analysis predicts response to anti-PD-1 immunotherapy. Nat Med. (2018) 24:144-53. doi: 10.1038/nm.4466

44. Gaublomme JT, Yosef N, Lee Y, Gertner RS, Yang LV, Wu C, et al. Single-cell genomics unveils critical regulators of Th17 cell pathogenicity. Cell. (2015) 163:1400-12. doi: 10.1016/j.cell.2015.11.009

45. Lee Y, Awasthi A, Yosef N, Quintana FJ, Xiao S, Peters A, et al. Induction and molecular signature of pathogenic TH17 cells. Nat Immunol. (2012) 13:991-9. doi: $10.1038 /$ ni.2416

46. Omenetti S, Bussi C, Metidji A, Iseppon A, Lee S, Tolaini M, et al. The intestine harbors functionally distinct homeostatic tissue-resident and inflammatory Th17 cells. Immunity. (2019) 51:77-89 e6. doi: 10.1016/j.immuni.2019.05.004

47. Zhao Q, Harbour SN, Kolde R, Latorre IJ, Tun HM, Schoeb TR, et al. Selective induction of homeostatic Th17 cells in the murine intestine by cholera toxin interacting with the microbiota. J Immunol. (2017) 199:312-22. doi: 10.4049/jimmunol.1700171
48. Wellenstein MD, de Visser KE. Cancer-cell-intrinsic mechanisms shaping the tumor immune landscape. Immunity. (2018) 48:399-416. doi: 10.1016/j.immuni.2018.03.004

49. Busch SE, Hanke ML, Kargl J, Metz HE, MacPherson D, Houghton AM. Lung cancer subtypes generate unique immune responses. J Immunol. (2016) 197:4493-503. doi: 10.4049/jimmunol.1600576

50. Van Allen EM, Miao D, Schilling B, Shukla SA, Blank C, Zimmer L, et al Genomic correlates of response to CTLA-4 blockade in metastatic melanoma. Science. (2015) 350:207-11. doi: 10.1126/science.aad0095

51. Rizvi NA, Hellmann MD, Snyder A, Kvistborg P, Makarov V, Havel JJ, et al. Cancer immunology. Mutational landscape determines sensitivity to PD-1 blockade in non-small cell lung cancer. Science. (2015) 348:124-8. doi: $10.1126 /$ science.aaal348

52. Thorsson V, Gibbs DL, Brown SD, Wolf D, Bortone DS, Ou Yang TH, et al. The immune landscape of cancer. Immunity. (2018) 48:812-30 e14. doi: 10.1016/j.immuni.2018.03.023

53. Dang CV, Kim JW. Convergence of cancer metabolism and immunity: an overview. Biomol Ther (Seoul). (2018) 26:4-9. doi: 10.4062/biomolther.2017.194

54. Morrot A, da Fonseca LM, Salustiano EJ, Gentile LB, Conde L, Filardy AA, et al. Metabolic symbiosis and immunomodulation: how tumor cell-derived lactate may disturb innate and adaptive immune responses. Front Oncol. (2018) 8:81. doi: 10.3389/fonc.2018.00081

55. Liu J, Cho SN, Akkanti B, Jin N, Mao J, Long W, et al. ErbB2 pathway activation upon Smad4 loss promotes lung tumor growth and metastasis. Cell Rep. (2015) 10:1599-613. doi: 10.1016/j.celrep.2015.02.014

56. Wislez M, Fujimoto N, Izzo JG, Hanna AE, Cody DD, Langley RR, et al. High expression of ligands for chemokine receptor CXCR2 in alveolar epithelial neoplasia induced by oncogenic kras. Cancer Res. (2006) 66:4198207. doi: 10.1158/0008-5472.CAN-05-3842

57. Pylayeva-Gupta Y, Lee KE, Hajdu CH, Miller G, Bar-Sagi D. Oncogenic kras-induced GM-CSF production promotes the development of pancreatic neoplasia. Cancer Cell. (2012) 21:836-47. doi: 10.1016/j.ccr.2012.04.024

58. McAllister F, Bailey JM, Alsina J, Nirschl CJ, Sharma R, Fan H, et al. Oncogenic kras activates a hematopoietic-to-epithelial IL-17 signaling axis in preinvasive pancreatic neoplasia. Cancer Cell. (2014) 25:621-37. doi: 10.1016/j.ccr.2014.03.014

59. Coffelt SB, Kersten K, Doornebal CW, Weiden J, Vrijland K, Hau CS, et al. IL17-producing gammadelta $\mathrm{T}$ cells and neutrophils conspire to promote breast cancer metastasis. Nature. (2015) 522:345-8. doi: 10.1038/nature14282

60. Li Q, Han Y, Fei G, Guo Z, Ren T, Liu Z. IL-17 promoted metastasis of non-small-cell lung cancer cells. Immunol Lett. (2012) 148:144-50. doi: 10.1016/j.imlet.2012.10.011

61. Yoon YK, Kim HP, Han SW, Oh DY, Im SA, Bang YJ, et al. KRAS mutant lung cancer cells are differentially responsive to MEK inhibitor due to AKT or STAT3 activation: implication for combinatorial approach. Mol Carcinog. (2010) 49:353-62. doi: 10.1002/mc.20607

62. Caetano MS, Zhang H, Cumpian AM, Gong L, Unver N, Ostrin EJ, et al. IL6 blockade reprograms the lung tumor microenvironment to limit the development and progression of K-ras-mutant lung cancer. Cancer Res. (2016) 76:3189-99. doi: 10.1158/0008-5472.CAN-15-2840

63. Martin-Orozco N, Muranski P, Chung Y, Yang XO, Yamazaki T, Lu S, et al. $\mathrm{T}$ helper 17 cells promote cytotoxic $\mathrm{T}$ cell activation in tumor immunity. Immunity. (2009) 31:787-98. doi: 10.1016/j.immuni.2009.09.014

64. Ganeshan K, Chawla A. Metabolic regulation of immune responses. Annu Rev Immunol. (2014) 32:609-34. doi: 10.1146/annurev-immunol-032713-120236

65. Loftus RM, Finlay DK. Immunometabolism: cellular metabolism turns immune regulator. J Biol Chem. (2016) 291:1-10. doi: $10.1074 /$ jbc.R115.693903

66. Quail DF, Joyce JA. Microenvironmental regulation of tumor progression and metastasis. Nat Med. (2013) 19:1423-37. doi: 10.1038/nm.3394

67. Ho PC, Liu PS. Metabolic communication in tumors: a new layer of immunoregulation for immune evasion. J Immunother Cancer. (2016) 4:4. doi: 10.1186/s40425-016-0109-1

68. Lyssiotis CA, Kimmelman AC. Metabolic interactions in the tumor microenvironment. Trends Cell Biol. (2017) 27:863-75. doi: $10.1016 /$ j.tcb.2017.06.003 
69. Kerr EM, Martins CP. Metabolic rewiring in mutant kras lung cancer. FEBS J. (2018) 285:28-41. doi: 10.1111/febs.14125

70. Kawada K, Toda K, Sakai Y. Targeting metabolic reprogramming in KRAS-driven cancers. Int J Clin Oncol. (2017) 22:651-9. doi: 10.1007/s10147-017-1156-4

71. Xie H, Hanai J, Ren JG, Kats L, Burgess K, Bhargava P, et al. Targeting lactate dehydrogenase-a inhibits tumorigenesis and tumor progression in mouse models of lung cancer and impacts tumor-initiating cells. Cell Metab. (2014) 19:795-809. doi: 10.1016/j.cmet.2014.03.003

72. Fischer K, Hoffmann P, Voelkl S, Meidenbauer N, Ammer J, Edinger M, et al. Inhibitory effect of tumor cell-derived lactic acid on human T cells. Blood. (2007) 109:3812-9. doi: 10.1182/blood-2006-07-035972

73. Haas R, Smith J, Rocher-Ros V, Nadkarni S, Montero-Melendez T, D'Acquisto F, et al. Lactate regulates metabolic and pro-inflammatory circuits in control of T cell migration and effector functions. PLoS Biol. (2015) 13:e1002202. doi: 10.1371/journal.pbio.1002202

74. Choi YK, Park KG. Targeting glutamine metabolism for cancer treatment. Biomol Ther (Seoul). (2018) 26:19-28. doi: 10.4062/biomolther.2017.178

75. Johnson MO, Wolf MM, Madden MZ, Andrejeva G, Sugiura A, Contreras DC, et al. Distinct regulation of Th17 and Th1 cell differentiation by glutaminase-dependent metabolism. Cell. (2018) 175:1780-95 e19. doi: 10.1016/j.cell.2018.10.001

76. Muranski P, Boni A, Antony PA, Cassard L, Irvine KR, Kaiser A, et al. Tumorspecific Th17-polarized cells eradicate large established melanoma. Blood. (2008) 112:362-73. doi: 10.1182/blood-2007-11-120998

77. Muranski P, Borman ZA, Kerkar SP, Klebanoff CA, Ji Y, Sanchez-Perez L, et al. Th17 cells are long lived and retain a stem cell-like molecular signature. Immunity. (2011) 35:972-85. doi: 10.1016/j.immuni.2011. 09.019

78. Paulos CM, Carpenito C, Plesa G, Suhoski MM, Varela-Rohena A, Golovina TN, et al. The inducible costimulator (ICOS) is critical for the development of human T(H)17 cells. Sci Transl Med. (2010) 2:55ra78. doi: 10.1126/scitranslmed.3000448
79. Goff SL, Dudley ME, Citrin DE, Somerville RP, Wunderlich JR, Danforth $\mathrm{DN}$, et al. Randomized, prospective evaluation comparing intensity of lymphodepletion before adoptive transfer of tumor-infiltrating lymphocytes for patients with metastatic melanoma. J Clin Oncol. (2016) 34:2389-97. doi: 10.1200/JCO.2016.66.7220

80. Cascone T, McKenzie JA, Mbofung RM, Punt S, Wang Z, Xu C, et al. Increased tumor glycolysis characterizes immune resistance to adoptive $\mathrm{T}$ cell therapy. Cell Metab. (2018) 27:977-87 e4. doi: 10.1016/j.cmet.2018.02.024

81. Sun L, Fu J, Zhou Y. Metabolism controls the balance of Th17/T-regulatory cells. Front Immunol. (2017) 8:1632. doi: 10.3389/fimmu.2017.01632

82. Duan MC, Zhong XN, Liu GN, Wei JR. The Treg/Th17 paradigm in lung cancer. J Immunol Res. (2014) 2014:730380. doi: 10.1155/2014/730380

83. Kimura A, Kishimoto T. IL-6: regulator of Treg/Th17 balance. Eur J Immunol. (2010) 40:1830-5. doi: 10.1002/eji.201040391

84. Zewde M, Kiyotani K, Park JH, Fang H, Yap KL, Yew PY, et al. The era of immunogenomics/immunopharmacogenomics. J Hum Genet. (2018) 63:86575. doi: 10.1038/s10038-018-0468-1

85. Wolf Y, Samuels Y. Cancer research in the era of immunogenomics. ESMO Open. (2018) 3:e000475. doi: 10.1136/esmoopen-2018-000475

86. Liu XS, Mardis ER. Applications of immunogenomics to cancer. Cell. (2017) 168:600-12. doi: 10.1016/j.cell.2017.01.014

Conflict of Interest: The authors declare that the research was conducted in the absence of any commercial or financial relationships that could be construed as a potential conflict of interest.

Copyright (C) 2019 Armstrong, Chang, Lazarus, Corry and Kheradmand. This is an open-access article distributed under the terms of the Creative Commons Attribution License (CC BY). The use, distribution or reproduction in other forums is permitted, provided the original author(s) and the copyright owner(s) are credited and that the original publication in this journal is cited, in accordance with accepted academic practice. No use, distribution or reproduction is permitted which does not comply with these terms. 